\title{
Combined Inhibition of ALK and HDAC Induces Synergistic Cytotoxicity in Neuroblastoma Cell Lines
}

\author{
KAZUMI HAGIWARA, TAKASHI TOKUNAGA, HIROATSU IIDA and HIROKAZU NAGAI \\ Clinical Research Center, National Hospital Organization Nagoya Medical Center, Nagoya, Japan
}

\begin{abstract}
Background/Aim: Neuroblastoma (NB) is the most common extracranial solid tumor in childhood; treatments with greater effectiveness are required for $N B$, especially in advanced cases. This study aimed at evaluating the combined effect of anaplastic lymphoma kinase (ALK) inhibitor alectinib and histone deacetylase inhibitor vorinostat on $N B$ cell lines harboring wild-type or mutated ALK. Materials and Methods: Cytotoxicity was examined using the 3-(4,5dimethylthiazol-2-yl)-2,5 diphenyltetrazolium bromide assay. Protein expression was analyzed using western blotting. Results: Combination treatment with alectinib and vorinostat had a synergistic effect on growth inhibition of the NB cell line with ALK R1275Q mutation. Cleavage of caspase-3 and poly-(ADP-ribose) polymerase increased, indicating enhanced caspase-dependent apoptosis. In addition, this combination reduced the protein levels of MYCN protooncogene and nuclear factor kappa B, both of which are important for NB tumorigenesis and progression. Conclusion: Combined treatment with alectinib and vorinostat might be a novel therapeutic option for $N B$ harboring the ALK R1275Q mutation.
\end{abstract}

Neuroblastoma (NB), the most common extracranial solid tumor in childhood, accounts for approximately $10 \%$ of all pediatric cancers and is responsible for $15 \%$ of deaths from cancer during childhood $(1,2)$. NB is classified into three groups based on patient age, disease stage, and molecular alterations: low, intermediate, and high risk. Low- and intermediate-risk NBs have excellent prognosis and outcome. However, despite recent advances in treatment approaches, the outcome of high-risk NB remains poor, with long-term survival being less than $50 \%$ (2). Therefore, novel therapeutic strategies need to be developed.

Correspondence to: Hirokazu Nagai, Clinical Research Center, National Hospital Organization Nagoya Medical Center, 4-1-1, Sannomaru, Naka-ku, Nagoya, Japan. E-mail: hirokazu.nagai@nnh.go.jp

Key Words: Neuroblastoma, ALK inhibitor, HDAC inhibitor, combination treatment, apoptosis.
Anaplastic lymphoma kinase (ALK) is a receptor tyrosine kinase that was initially identified as part of a chromosomal translocation associated with anaplastic large-cell lymphoma (3). In the case of $A L K$ fusion proteins generated by chromosomal rearrangements, constitutive activation of ALK and various downstream signaling pathways are noted, which consequently lead to tumorigenesis and cancer progression (4). In 2008, activating mutations of $A L K$ were identified in both familial and sporadic cases of NB (5-8); these mutations are thought to be important in NB development. Therefore, ALK-targeted therapy has been considered promising for NB. However, the clinical effects of ALK inhibitors have been limited, especially against $A L K$-mutated NB (9). Moreover, secondary mutations have been noted after treatment with ALK inhibitors, as has been seen with other tyrosine-kinase inhibitors (10).

Combination strategies that target different molecules or signaling pathways are useful approaches to increase the efficacy of agents such as ALK inhibitors. Many studies have investigated the effect of combining ALK inhibitors with other chemotherapeutics and agents targeting specific molecules (1113). These studies reported a synergistic improvement in therapeutic efficacy on using combination treatments. Targeting of epigenetic regulation, such as DNA methylation or histone modification, is a good candidate for such combination strategies. In particular, the antitumor effect of histone deacetylase (HDAC) inhibitors, agents that target the regulation of histone acetylation, has been well studied in hematological and solid tumors (14). In vitro studies have shown that HDAC inhibitors such as vorinostat and romidepsin significantly inhibit cell growth and induce apoptosis in NB $(15,16)$.

In the current study, we investigated the effect of combining alectinib, a second-generation ALK inhibitor developed to overcome crizotinib resistance (17), with vorinostat, the first HDAC inhibitor approved for the treatment of cutaneous T-cell lymphoma (18), on NB cell lines harboring wild-type or mutated ALK.

\section{Materials and Methods}

Reagents and cell lines. The ALK inhibitor alectinib and the HDAC inhibitor vorinostat were purchased from Selleck Chemicals, LLC (Houston, TX, USA). Drugs were prepared in dimethyl sulfoxide 
(DMSO) at a concentration of $1 \mathrm{mM}$ for alectinib and $10 \mathrm{mM}$ for vorinostat. The following NB cell lines were used: SK-N-AS (NB cell line with wild-type $A L K$ ) and SK-N-SH (NB cell line with $A L K$ F1174L mutation), obtained from the American Type Culture Collection (Rockville, MD, USA), and LA-N-5 (NB cell line with $A L K$ R1275Q mutation), obtained from the Children's Oncology Group Cell Culture and Xenograft Repository (Lubbock, TX, USA). The cell lines were cultured in the following media: SK-N-AS cells were cultured in Dulbecco's Modified Eagle Medium (Sigma, St. Louis, MO, USA) supplemented with $10 \%$ fetal bovine serum (FBS) and $0.1 \mathrm{mM}$ non-essential amino acids; SK-N-SH cells in Eagle's minimum essential medium (Sigma) supplemented with 10\% FBS; and LA-N-5 cells in RPMI-1640 (Sigma) supplemented with $10 \%$ FBS. All cell lines were maintained in a humid atmosphere with $5 \% \mathrm{CO}_{2}$ at $37^{\circ} \mathrm{C}$.

Analysis of cell proliferation. Cell proliferation was analyzed using the 3-(4,5-dimethylthiazol-2-yl)-2,5-diphenyltetrazolium bromide (MTT) assay (Cell Titer 96 AQUEOUS One Solution Cell Proliferation Assay; Promega, Madison, WI, USA) according to the manufacturer's instructions. NB cells were seeded in 96-well plates and incubated overnight to permit attachment. The cells were then treated for 48 hours with alectinib and vorinostat alone or in combination. SK-N-AS cells were treated with $3.3 \mu \mathrm{M}$ alectinib combined with $7 \mu \mathrm{M}$ vorinostat, corresponding to a fixed ratio of 3.3:7. SK-N-SH cells were treated with $1.6 \mu \mathrm{M}$ alectinib combined with $3.4 \mu \mathrm{M}$ vorinostat, corresponding to a fixed ratio of $8: 17$. LA-N-5 cells were treated with $0.6 \mu \mathrm{M}$ alectinib combined with $1 \mu \mathrm{M}$ vorinostat, corresponding to a fixed ratio of 3:5. The viability of drug-treated cells was expressed as a percentage of that of the untreated controls. All experiments were performed in triplicate and were repeated for a total of three independent experiments.

Western blotting. Cells were cultured and treated before being lysed in radioimmunoprecipitation assay buffer (Pierce, Rockford, IL, USA) containing both the protease inhibitor Complete (Roche Diagnostics, GmbH, Mannheim Germany) and the phosphatase inhibitor PhosSTOP (Roche Diagnostics). Cell lysates (20 $\mu \mathrm{g}$ proteins) were separated by sodium dodecyl sulfate-polyacrylamide gel electrophoresis and transferred to polyvinylidene difluoride membranes. The resulting blots were blocked with $5 \%(\mathrm{w} / \mathrm{v})$ nonfat dry milk or bovine serum albumin and then probed with the following primary antibodies (Cell Signaling Technology, Beverly, MA, USA): anti-caspase-3, anti-poly-(ADP-ribose) polymerase (PARP), anti-nuclear factor kappa B subunit 1 (NF-kB1) p105/p50, and anti-MYCN proto-oncogene (MYCN). The membranes were then washed with Tris-buffered saline containing $0.05 \%$ Tween 20 before being incubated with the secondary antibody, namely horseradish peroxidase-conjugated goat anti-rabbit IgG (Cell Signaling Technology). The signal was detected using the ECL Prime Western Blotting Detection System and an ImageQuant LAS 4000 instrument (GE Healthcare UK, Buckinghamshire, UK). Anti- $\beta$-actin (Sigma) was used as a loading control.

Statistical analysis. All experiments were performed at least three times. Results are expressed in terms of mean \pm standard deviation (SD) values. Excel-Toukei 2010 (Social Survey Research Information, Tokyo, Japan) was used for statistical analysis. A $p$ value of less than 0.05 was considered statistically significant.
Table I. The median-effect doses (Dm), i.e. the dose at which growth was $50 \%$ of that in the untreated control, for each neuroblastoma cell line as determined using CalcuSyn software.

\begin{tabular}{lccc}
\hline Cell line & \multirow{2}{*}{ ALK status } & \multicolumn{2}{c}{ Dm $(\mu \mathrm{M})$} \\
\cline { 3 - 4 } & & Alectinib & Vorinostat \\
\hline SK-N-AS & Wild-type & 3.2973 & 7.0844 \\
SK-N-SH & F1174L & 1.5635 & 3.3818 \\
LA-N-5 & R1275Q & 0.6258 & 0.9667 \\
\hline
\end{tabular}

$A L K$ : Anaplastic lymphoma kinase.

Drug interactions were analyzed on the basis of the median-effect method as described by Chou and Talalay (19). CalcuSyn version 2.0 (Biosoft, Cambridge, UK) was used to calculate and plot the combination index $(\mathrm{CI})$, which is a quantitative measure of the degree of drug interaction. CI $<1$ indicates synergism, CI=1 indicates an additive effect, and $\mathrm{CI}>1$ indicates an antagonistic effect. Data obtained from the cell proliferation assay were used to perform this analysis.

\section{Results}

Synergistic growth inhibition of ALK R1275Q-mutated NB cell line by the alectinib and vorinostat combination. The three NB cell lines SK-N-AS, SK-N-SH, and LA-N-5 were treated for 48 hours with different concentrations of either alectinib or vorinostat alone. Dm, the median-effect dose of each inhibitor, was then determined using CalcuSyn software (Table I). The $A L K$-mutated NB cell lines, SK-N-SH and LA$\mathrm{N}-5$, were more sensitive to both inhibitors than were SK-NAS cells, which harbor wild-type $A L K$. SK-N-SH cells, which harbor F1174L-mutated $A L K$, had a higher Dm, that is, relative resistance, to alectinib than did the LA-N-5 cells, which expressed R1275Q-mutated $A L K$; this elevation in Dm is consistent with the findings of a previous study (20).

To improve the efficacy obtained with the use of a single agent, we treated the NB cell lines with a combination of alectinib and vorinostat. For the combination, we used fixed ratios of drug concentrations corresponding to the respective Dm dose of each agent. We used the following fixed ratios of alectinib:vorinostat: 3.3:7 for SK-N-AS cells, 8:17 for SK$\mathrm{N}-\mathrm{SH}$ cells, and 3:5 for LA-N-5 cells. After 48-h exposure, the combination treatment considerably reduced cell viability of each of the cell lines examined (Figure 1, left panel). To evaluate possible synergism, CI values were calculated using CalcuSyn software. For SK-N-AS and SK-N-SH cells, the $\mathrm{CI}$ values were higher than 1.0 (Figure $1 \mathrm{~A}$ and $\mathrm{B}$, right panel). However, for LA-N-5 cells, the CI values were less than 1.0, indicating a synergistic interaction (Figure 1C, right panel). These data suggest that the combination of alectinib and vorinostat would be efficacious against NB cells, notably in NB harboring the $A L K \mathrm{R} 1275 \mathrm{Q}$ mutation. 

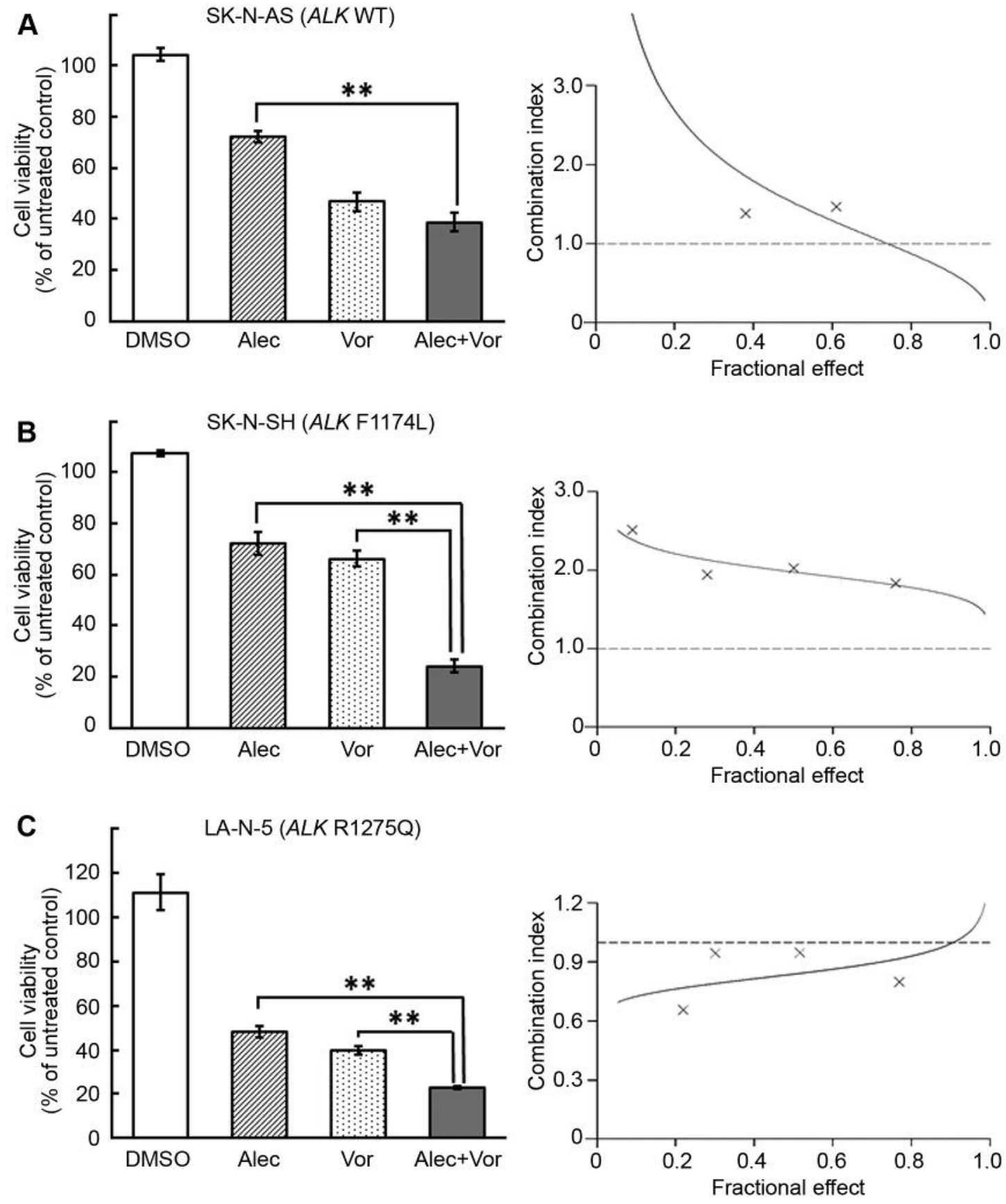

Figure 1. Effect of combination treatment with alectinib (Alec) and vorinostat (Vor) on cell proliferation of $S K-N-A S(A), S K-N-S H(B), L A-N-5$ (C) neuroblastoma $(N B)$ cell lines. Left panel: $N B$ cells were treated for $48 \mathrm{~h}$ with alectinib and vorinostat, alone or in combination, and cell viability was then measured using the MTT assay. Results are presented as the mean $\pm S D$ values of three independent experiments, each performed in triplicate. WT, Wild-type. Right panel: Combination index (CI) plots for alectinib and vorinostat were generated with the CalcuSyn software. CI values $<1.0$ correspond to synergistic interactions. The dotted lines indicate CI values of 1.0. **Significantly different at $p<0.01$.

The alectinib and vorinostat combination induced caspasedependent apoptosis. To determine whether the growth inhibition induced by the combination of alectinib and vorinostat involved apoptosis, we assessed the expression of apoptosis-related proteins by western blotting. The combination treatment increased the expression levels of cleaved caspase-3 and PARP in LA-N-5 cells (Figure 2). These results suggest that the combination enhanced the induction of caspase-dependent apoptosis. 


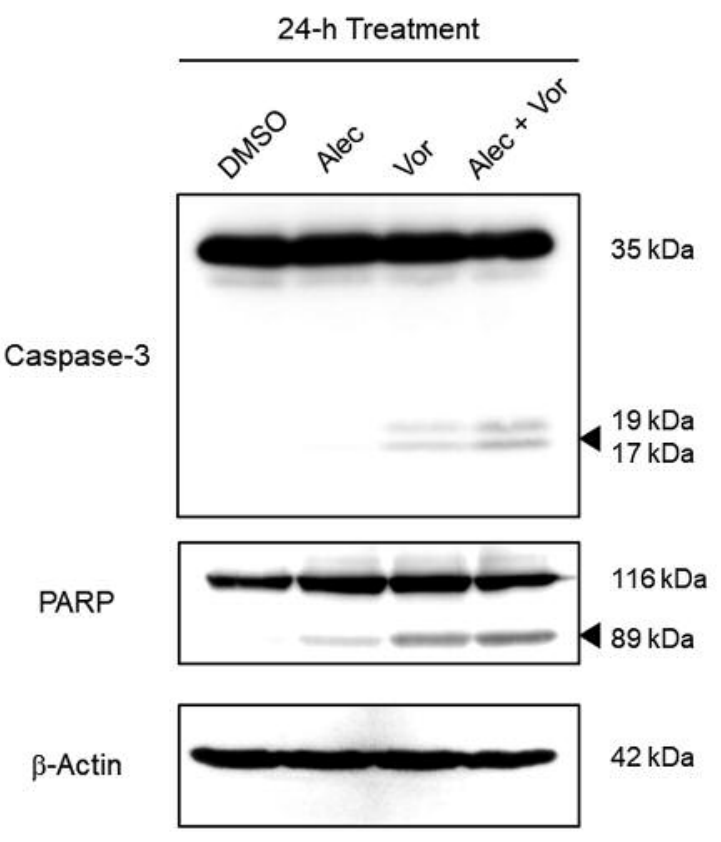

Figure 2. Combined treatment with alectinib (Alec) and vorinostat (Vor) increased apoptosis of neuroblastoma cells. LA-N-5 cells were treated with $0.6 \mu M$ alectinib with/without $1 \mu M$ vorinostat for $24 h$, and expression of caspase-3 and poly-(ADP-ribose) polymerase (PARP), was then analyzed by western blotting. Arrowheads indicate the cleaved forms of caspase- 3 and PARP, which are hallmarks of apoptosis. $\beta$-Actin was used as the loading control. DMSO: Dimethyl sulfoxide (vehicle).

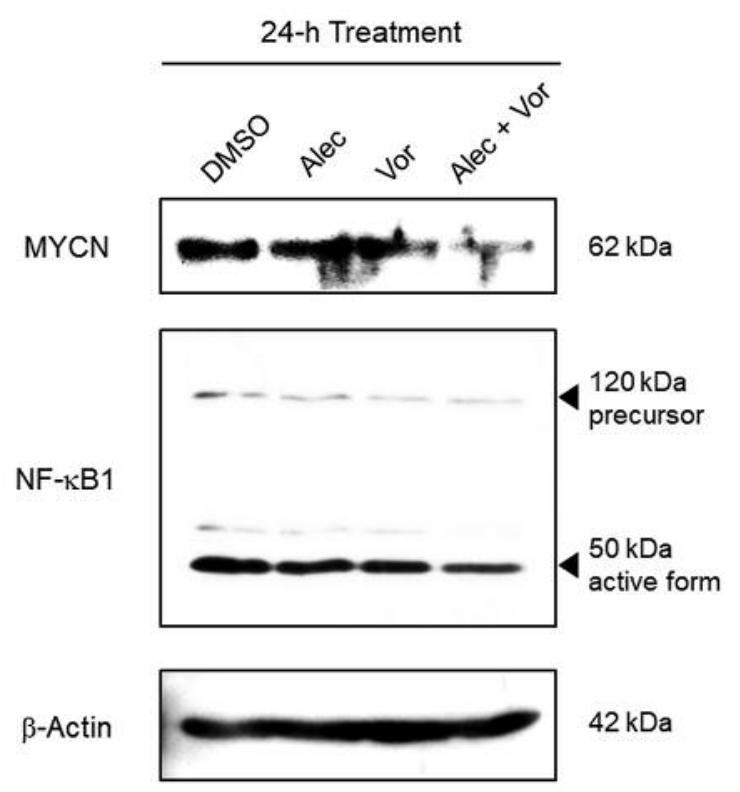

Figure 3. Combined treatment with alectinib (Alec) and vorinostat (Vor) inhibited protein expression of MYCN proto-oncogene (MYCN) and nuclear factor-kappa B subunit $1(\mathrm{NF}-\mathrm{kB} 1) / \mathrm{p} 105$. LA-N-5 cells were treated for $24 \mathrm{~h}$ with $0.6 \mu \mathrm{M}$ alectinib with/without $1 \mu \mathrm{M}$ vorinostat, and expression of MYCN and NF-KB1/p105 was then analyzed by western blotting. In the panel for $N F-k B 1$, arrowheads indicate the inactive precursor 105 and the mature processed form p50. $\beta$-Actin was used as the loading control.
Combination treatment reduced MYCN and NF-kB1/p105 expression. MYCN amplification is a hallmark of poor prognosis in high-risk NB. Down-regulation of $M Y C N$ expression and activity has been shown to correlate with an increase in apoptosis and differentiation, leading to suppression of cell growth (21). We examined the effect of the combination treatment on MYCN and NF-kB1/p105 protein expression. Although we did not observe any effects on treatment with either alectinib or vorinostat alone, the combination treatment did reduce MYCN and NF-kB1/p105 protein levels (Figure 3).

\section{Discussion}

The clinical effects of crizotinib, a well-studied ALK inhibitor, and vorinostat, against NB, have been previously studied $(9,22)$; the results of these clinical trials suggested that neither crizotinib nor vorinostat alone is sufficient for suppressing NB tumor growth. Therefore, we tested the combination of alectinib and vorinostat against NB cell lines expressing wild-type $A L K$ or with hot-spot mutations of $A L K$ (F1174L or R1275Q). Compared to the effects obtained with either compound alone, co-treatment with alectinib and vorinostat significantly reduced the viability of all the NB cell lines tested. However, the combination treatment did not have a synergistic effect on cell lines harboring wild-type or F1174L-mutated $A L K$. Some studies have reported that the F1174L mutation is associated with resistance to ALK inhibitors. Bresler et al. revealed that the F1174L mutation increases the ATP affinity of ALK and reduces sensitivity to crizotinib $(20,23)$. In addition, Berry et al. showed that the F1174L mutation frequently occurs in $M Y C N$-amplified tumors and potentiates the oncogenic effect of MYCN in NB (24). These studies suggested that the F1174L-mutated protein has higher specific activity than other forms of ALK, including the R1275Q-mutated protein, which would lead to the distinct susceptibility of the various cell lines to the alectinib and vorinostat combination noted in our study.

We also searched for characteristic changes in protein levels in response to treatment with the combination of alectinib and vorinostat. We found that the expression of MYCN and NF-kB1/p105 proteins, which are considered important factors for NB tumorigenesis and progression, was attenuated following combination treatment. MYCN is a member of the MYC transcription factor family, which 
comprises proteins that regulate various cellular processes including cell proliferation and the cell cycle (25). MYCN gene amplification is observed in $20 \%$ of all NB cases and is especially prevalent in patients whose disease is resistant to therapy and who have a poor prognosis (26). Several studies have indicated that treatment with inhibitors of either ALK or HDAC reduces MYCN expression but that this effect is moderate and temporary $(15,27)$. Our results suggest that dual inhibition by ALK and HDAC would suppress MYCN expression. NF-kB, another factor that was down-regulated by combination treatment in our study, plays an important role in controlling cell proliferation, adhesion, invasion, and metastasis. Elevated NF-kB activity has been observed in many cancer types, including NB $(28,29)$. NF-kB1 ( $105 / \mathrm{p} 50)$ is an inactive precursor that is processed by the proteasome to yield the mature p50 transcription factor. Using a mantle cell lymphoma cell line, we previously showed that treatment with a combination of a tyrosine kinase inhibitor and vorinostat reduced the expression of both precursor NF-kB1/p105 and the active p50 subunit, suggesting inhibition of the NF-kB signaling pathway (30). Similarly, the current study showed that the combination of alectinib and vorinostat reduced expression of both NF$\mathrm{kB} 1 / \mathrm{p} 105$ and p50 (Figure 3). Taken together, these results suggest that treatment with a combination of a tyrosine kinase inhibitor and an HDAC inhibitor may impair tumor growth by modulating expression of the components of the NF-kB signaling pathway.

To our knowledge, the current study is the first to show the efficacy of a combination of ALK and HDAC inhibitors against NB. Our preclinical data provide evidence suggesting that the combination of alectinib and vorinostat induces apoptosis and growth inhibition in NB cell lines and that the effect may be mediated via changes in the expression of factors such as MYCN and NF- $\mathrm{KB}$. Further studies will be required to define better the precise mechanism(s) whereby the combination of alectinib and vorinostat modulates the expression and activity of the genes studied here. Our findings suggest that combined inhibition of ALK and HDAC may serve as a novel approach for treating refractory/relapsed NB with mutated $A L K$.

\section{Conflicts of Interest}

The Authors declare no conflicts of interest regarding this study.

\section{Authors' Contributions}

$\mathrm{KH}$ performed the majority of the study experiments and wrote the article. TT and HI participated in data interpretation. HN conceived and designed the study, and contributed to data interpretation. All Authors read and approved the final article.

\section{Acknowledgements}

The current study was supported by the Research Program on HIV/AIDS (grant no. 18fk0410008h0003) from the Japan Agency for Medical Research and Development (AMED).

\section{References}

1 Maris JM: Recent advances in neuroblastoma. N Engl J Med 362(23): 2202-2211, 2010. PMID: 20558371. DOI: 10.1056/ NEJMra0804577

2 Whittle SB, Smith V, Doherty E, Zhao S, McCarty S and Zage PE: Overview and recent advances in the treatment of neuroblastoma. Expert Rev Anticancer Ther 17(4): 369-386, 2017. PMID: 28142287. DOI: 10.1080/14737140.2017.1285230

3 Morris SW, Kirstein MN, Valentine MB, Dittmer KG, Shapiro DN, Saltman DL and Look AT: Fusion of a kinase gene, $A L K$, to a nucleolar protein gene, $N P M$, in non-hodgkin's lymphoma. Science 263(5151): 1281-1284, 1994. PMID: 8122112.

4 Roskoski R Jr.: Anaplastic lymphoma kinase (ALK): Structure, oncogenic activation, and pharmacological inhibition. Pharmacol Res 68(1): 68-94, 2013. PMID: 23201355. DOI: 10.1056/ j.phrs.2012.11.007

5 Chen Y, Takita J, Choi YL, Kato M, Ohira M, Sanada M, Wang L, Soda M, Kikuchi A, Igarashi T, Nakagawara A, Hayashi Y, Mano $\mathrm{H}$ and Ogawa S: Oncogenic mutations of $A L K$ kinase in neuroblastoma. Nature 455(7215): 971-974, 2008. PMID: 18923524. DOI: $10.1038 /$ nature07399

6 George RE, Sanda T, Hanna M, Fröhling S, Ii WL, Zhang J, Ahn Y, Zhou W, London WB, McGrady P, Xue L, Zozulya S, Gregor VE, Webb TR, Gray NS, Gilliland DG, Diller L, Greulich H, Morris SW, Meyerson M and Look AT: Activating mutations in $A L K$ provide a therapeutic target in neuroblastoma. Nature 455(7215): 975-978, 2008. PMID: 18923525. DOI: 10.1038/ nature 07397

7 Janoueix-Lerosey I, Lequin D, Brugières L, Ribeiro A, de Pontual L, Combaret V, Raynal V, Puisieux A, Schleiermacher G, Pierron G, Valteau-Couanet D, Frebourg T, Michon J, Lyonnet S, Amiel J and Delattre O: Somatic and germline activating mutations of the $A L K$ kinase receptor in neuroblastoma. Nature 455(7215): 967970, 2008. PMID: 18923523. DOI: 10.1038/nature07398

8 Mossé YP, Laudenslager M, Longo L, Cole KA, Wood A, Attiyeh EF, Laquaglia MJ, Sennett R, Lynch JE, Perri P, Laureys G, Speleman F, Kim C, Hou C, Hakonarson H, Torkamani A, Schork NJ, Brodeur GM, Tonini GP, Rappaport E, Devoto M and Maris JM: Identification of $A L K$ as a major familial neuroblastoma predisposition gene. Nature 455(7215): 930-935, 2008. PMID: 18724359 . DOI: $10.1038 /$ nature07261

9 Mossé YP, Lim MS, Voss SD, Wilner K, Ruffner K, Laliberte J, Rolland D, Balis FM, Maris JM, Weigel BJ, Ingle AM, Ahern C, Adamson PC and Blaney SM: Safety and activity of crizotinib for paediatric patients with refractory solid tumours or anaplastic large-cell lymphoma: A Children's Oncology Group phase 1 consortium study. Lancet Oncol 14(6): 472-480, 2013. PMID: 23598171. DOI: 10.1016/S1470-2045(13)70095-0

10 Jiao Q, Bi L, Ren Y, Song S, Wang Q and Wang YS: Advances in studies of tyrosine kinase inhibitors and their acquired resistance. Mol Cancer 17(1): 36, 2018. PMID: 29455664. DOI: 10.1186/s12943-018-0801-5 
11 Krytska K, Ryles HT, Sano R, Raman P, Infarinato NR, Hansel TD, Makena MR, Song MM, Reynolds CP and Mosse YP: Crizotinib synergizes with chemotherapy in preclinical models of neuroblastoma. Clin Cancer Res 22(4): 948-960, 2016. PMID: 26438783. DOI: 10.1158/1078-0432.CCR-15-0379

12 Moore NF, Azarova AM, Bhatnagar N, Ross KN, Drake LE, Frumm S, Liu QS, Christie AL, Sanda T, Chesler L, Kung AL, Gray NS, Stegmaier K and George RE: Molecular rationale for the use of PI3K/AKT/MTOR pathway inhibitors in combination with crizotinib in $A L K$-mutated neuroblastoma. Oncotarget 5(18): 8737-8749, 2014. PMID: 25228590. DOI: 10.18632/ oncotarget.2372

13 Wang HQ, Halilovic E, Li X, Liang J, Cao Y, Rakiec DP, Ruddy DA, Jeay S, Wuerthner JU, Timple N, Kasibhatla S, Li N, Williams JA, Sellers WR, Huang A and Li F: Combined $A L K$ and $M D M 2$ inhibition increases antitumor activity and overcomes resistance in human $A L K$-mutant neuroblastoma cell lines and xenograft models. eLife 6: e17137, 2017. PMID: 28425916. DOI: $10.7554 /$ eLife. 17137

14 Ververis K, Hiong A, Karagiannis TC and Licciardi PV: Histone deacetylase inhibitors (HDACIs): Multitargeted anticancer agents. Biologics 7: 47-60, 2013. PMID: 23459471. DOI: 10.2147/BTT.S29965

15 Cortes C, Kozma SC, Tauler A and Ambrosio S: MYCN concurrence with SAHA-induced cell death in human neuroblastoma cells. Cell Oncol 38(5): 341-352, 2015. PMID: 26306783. DOI: $10.1007 / \mathrm{s} 13402-015-0233-9$

16 Hegarty SV, Togher KL, O'Leary E, Solger F, Sullivan AM and O'Keeffe GW: Romidepsin induces caspase-dependent cell death in human neuroblastoma cells. Neurosci Lett 653: 12-18, 2017. PMID: 28506690. DOI: 10.1016/j.neulet.2017.05.025

17 Sakamoto H, Tsukaguchi T, Hiroshima S, Kodama T, Kobayashi T, Fukami TA, Oikawa N, Tsukuda T, Ishii N and Aoki Y: CH5424802, a selective ALK inhibitor capable of blocking the resistant gatekeeper mutant. Cancer Cell 19(5): 679-690, 2011. PMID: 21575866. DOI: 10.1016/j.ccr.2011.04.004

18 Mann BS, Johnson JR, Cohen MH, Justice R and Pazdur R: FDA approval summary: Vorinostat for treatment of advanced primary cutaneous T-cell lymphoma. Oncologist 12(10): 12471252, 2007. PMID: 17962618. DOI: 10.1634/theoncologist.1210-1247

19 Chou TC and Talalay P: Quantitative analysis of dose-effect relationships: The combined effects of multiple drugs or enzyme inhibitors. Adv Enzyme Regul 22: 27-55, 1984. PMID: 6382953.

20 Bresler SC, Wood AC, Haglund EA, Courtright J, Belcastro LT, Plegaria JS, Cole K, Toporovskaya Y, Zhao H, Carpenter EL, Christensen JG, Maris JM, Lemmon MA and Mosse YP: Differential inhibitor sensitivity of anaplastic lymphoma kinase variants found in neuroblastoma. Sci Transl Med 3(108): 108ra114, 2011. PMID: 22072639. DOI: 10.1126/scitranslmed. 3002950

21 Johnsen JI, Dyberg C, Fransson S and Wickstrom M: Molecular mechanisms and therapeutic targets in neuroblastoma. Pharmacol Res 131: 164-176, 2018. PMID: 29466695. DOI: 10.1016/ j.phrs.2018.02.023
22 Fouladi M, Park JR, Stewart CF, Gilbertson RJ, Schaiquevich P, Sun J, Reid JM, Ames MM, Speights R, Ingle AM, Zwiebel J, Blaney SM and Adamson PC: Pediatric phase I trial and pharmacokinetic study of vorinostat: A Children's Oncology Group phase I consortium report. J Clin Oncol 28(22): 36233629, 2010. PMID: 20606092. DOI: 10.1200/JCO.2009.25.9119

23 Bresler SC, Weiser DA, Huwe PJ, Park JH, Krytska K, Ryles H, Laudenslager M, Rappaport EF, Wood AC, McGrady PW, Hogarty MD, London WB, Radhakrishnan R, Lemmon MA and Mosse YP: $A L K$ mutations confer differential oncogenic activation and sensitivity to $A L K$ inhibition therapy in neuroblastoma. Cancer Cell 26(5): 682-694, 2014. PMID: 25517749. DOI: 10.1016/j.ccell.2014.09.019

24 Berry T, Luther W, Bhatnagar N, Jamin Y, Poon E, Sanda T, Pei D, Sharma B, Vetharoy WR, Hallsworth A, Ahmad Z, Barker K, Moreau L, Webber H, Wang W, Liu Q, Perez-Atayde A, Rodig S, Cheung NK, Raynaud F, Hallberg B, Robinson SP, Gray NS, Pearson AD, Eccles SA, Chesler L and George RE: The $A L K(\mathrm{~F} 1174 \mathrm{~L})$ mutation potentiates the oncogenic activity of MYCN in neuroblastoma. Cancer Cell 22(1): 117-130, 2012. PMID: 22789543. DOI: 10.1016/j.ccr.2012.06.001

25 Huang $M$ and Weiss WA: Neuroblastoma and MYCN. Cold Spring Harb Perspect Med 3(10): a014415, 2013. PMID: 24086065. DOI: 10.1101/cshperspect.a014415

26 Valter K, Zhivotovsky B and Gogvadze V: Cell death-based treatment of neuroblastoma. Cell Death Dis 9(2): 113, 2018. PMID: 29371588. DOI: 10.1038/s41419-017-0060-1

27 Guan J, Tucker ER, Wan H, Chand D, Danielson LS, Ruuth K, El Wakil A, Witek B, Jamin Y, Umapathy G, Robinson SP, Johnson TW, Smeal T, Martinsson T, Chesler L, Palmer RH and Hallberg B: The $A L K$ inhibitor PF-06463922 is effective as a single agent in neuroblastoma driven by expression of ALK and MYCN. Dis Model Mech 9(9): 941-952, 2016. PMID: 27483357. DOI: $10.1242 / \mathrm{dmm} .024448$

28 Xia Y, Shen S and Verma IM: NF-kappaB, an active player in human cancers. Cancer Immunol Res 2(9): 823-830, 2014. PMID: 25187272. DOI: 10.1158/2326-6066.CIR-14-0112

29 Zhi Y, Lu H, Duan Y, Sun W, Guan G, Dong Q and Yang C: Involvement of the nuclear factor-kappaB signaling pathway in the regulation of $\mathrm{CXC}$ chemokine receptor- 4 expression in neuroblastoma cells induced by tumor necrosis factor-alpha. Int J Mol Med 35(2): 349-357, 2015. PMID: 25503960. DOI: $10.3892 /$ ijmm.2014.2032

30 Hagiwara K, Kunishima S, Iida H, Miyata Y, Naoe T and Nagai $\mathrm{H}$ : The synergistic effect of BCR signaling inhibitors combined with an HDAC inhibitor on cell death in a mantle cell lymphoma cell line. Apoptosis 20(7): 975-985, 2015. PMID: 25835755. DOI: $10.1007 / \mathrm{s} 10495-015-1125-1$ 